\title{
Idiopathic dilated cardiomyopathy in pregnancy
}

\author{
João Paulo Cândido Barbosa ${ }^{1}$, Maria Regina Melo da Justa Feijão ${ }^{1}$, \\ Francisco Herlanio Costa Carvalho ${ }^{2}$, Carlos Augusto Alencar Jr. ${ }^{2}$, \\ Francisco Edson de Lucena Feitosa ${ }^{2}$ \\ ${ }^{1}$ Federal University of Ceara, Fortaleza, Brazil \\ ${ }^{2}$ Department of Obstetrics, Federal University of Ceara, Fortaleza, Brazil \\ Email:jpaulo_barbosa@hotmail.com
}

Received 19 March 2013; revised 20 April 2013; accepted 30 April 2013

Copyright (C 2013 João Paulo Cândido Barbosa et al. This is an open access article distributed under the Creative Commons Attribution License, which permits unrestricted use, distribution, and reproduction in any medium, provided the original work is properly cited.

\begin{abstract}
The aim of this study was to highlight the importance of knowledge of idiopathic dilated cardiomyopathy (IDC) in pregnancy and its complications, with the order to establish early diagnosis and treatment. We report the case of a primigravida aged 17 , previously healthy, 18 weeks of gestation with dyspnea at rest, which started 2 weeks ago. During the investigation, the echocardiogram (ECO) showed left ventricle (LV) dilation with impaired systolic and diastolic function, LV ejection fraction of $20 \%$. We did not identify a cause for the patient's clinical condition, being diagnosed with IDC. The patient remained in obstetrics and cardiology monitoring for up to 23 weeks of gestation, when it was decided by the interruption of pregnancy by caesarean section due to hemodynamic instability. The newborn came to death four days after the procedure. The patient evolved to clinical improvement, 16 days after the resolution of gestation, was discharged for outpatient monitoring.
\end{abstract}

Keywords: Cardiomyopathy; Pregnancy; Dyspnea at Rest; Caesarean Section

\section{INTRODUCTION}

Idiopathic dilated cardiomyopathy (IDC) is a disease of unknown cause that affects the heart muscle. The changes are predominant cardiomegaly with dilatation of one or both ventricles and impaired systolic function, due to reduction in ventricular contractility [1-3].

The occurrence of idiopathic dilated cardiomyopathy (IDC) in pregnancy has been rarely reported in the literature [4-7]. In many cases, evolution can be fatal in a short time, highlighting the importance of diagnosis and clinical management and obstetrics [1-3,6].

\section{CASE REPORT}

Patient aged 17, mulatto, stable, working in the textile industry, born and raised in Fortaleza, primigravida with 18 weeks pregnant, was admitted to the emergency of Maternidade Escola Assis Chateaubriand (MEAC) Hospital, on 07.12.2012, with dyspnea at rest. Family reported that the patient had been healthy with no history of heart disease or lung prior, when 02 weeks ago, initiated a progressive dyspnea, cough, and asthenia. On physical examination, the emergence of MEAC, the patient was agitated, tachydyspnea with use of accessory muscles, profuse sweating, jugular venous distention, mucocutaneous pallor $(3+/ 4+)$ and edema in the lower limbs $(2+/ 4+)$. The parameters were changed with respiratory rate of $42 \mathrm{bpm}$, heart rate of $130 \mathrm{bpm}$, blood pressure of $130 \times 90 \mathrm{mmHg}$ and oxygen saturation of $93 \%$ on room air. On auscultation, had reduced breath sounds with crackles predominantly right up the middle third of both hemithorax. On cardiac auscultation, there was a tachycardic rhythm without murmurs audible. On palpation of the abdomen, the uterus was found 2 inches below the navel.

Because of the severity, the patient was transferred to the intensive care unit (ICU) of MEAC, which evolved with acute pulmonary edema, requiring intubation for respiratory support and the use of diuretics to reverse the situation. Chest radiography (Figure 1) showed an increase in the cardiac area with bulging pulmonary trunk. Electrocardiogram showed right and left atrial enlargement and hypertrophy of the LV.

In the ICU, the ECO was performed which showed LV dilation with impaired systolic and diastolic function, LV ejection fraction of $20 \%$, estimated pulmonary artery pressure by $12.8 \mathrm{mmHg}$, mild mitral regurgitation and absence of intracavitary masses or vegetations. Given the improvement of the general, the patient was discharged 


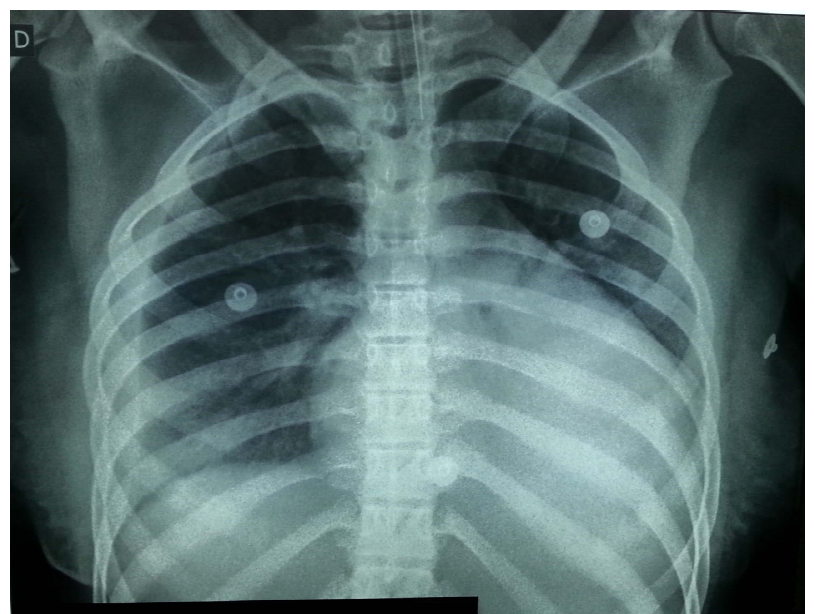

Figure 1. Chest radiography.

from the ICU to the ward Obstetric, on 14.12.2012, with a diagnosis of IDC.

In the ward, the patient remained asymptomatic, being decided in discussion with Cardiology start Isordil (10 $\mathrm{mg}, 3$ times a day) and hydralazine (25 mg q12h), associated with carvedilol (3.125 mg q12h), as clinical management of heart failure. Were requested viral serology, autoimmune disease and Chagas disease, all with negative results, thyroid function tests, with $\mathrm{TSH}=3.53$ and free $\mathrm{T} 4=1.02$, and the kinetics of iron, ferritin $=597.4$ and transferrin saturation index $=15 \%$.

The patient was followed up by cardiology and obstetrics. Due to the increased risk of thromboembolic events, Heparin was started to obtain a value for the APTT between 1.5 and 2.5. Then it was added to warfarin (5 $\mathrm{mg} /$ day) in order to achieve a value for the INR between 2 and 3.

The patient continued treatment in the obstetric ward, introducing 2 new episodes of frank respiratory failure, which required transfer to the obstetric ICU for stabilization. On 14.01.2013, in joint decision between Obstetrics and Cardiology, was decided by resolution of gestation by caesarean section. The next day, the cesarean was performed uneventfully. The baby was born at 23 weeks and 4 days, with death coming four days after the procedure due to respiratory failure and extreme prematurity.

For 16 days, the patient remained hospitalized for stabilization of respiratory and heart, and was discharged on 31.1.2013, using captopril (100 mg/day), spironolactone (25 mg/day) and carvedilol (6.25 mg/day).

\section{DISCUSSION}

Given the above case, this paper observes a patient with IDC confirmed by echocardiography, which became symptomatic in the 1st half of pregnancy without an identifiable cause for the clinical picture described. She did not meet the criteria for peripartum cardiomyopathy
(PC), a disease that affects the heart muscle and is best described in the literature [8,9].

Van Hoeven et al. showed that in patients with rapid clinical deterioration, PC had a lower survival rate. In PC death in patients with low clinical response occurred after an average of 9 months or less of disease. In contrast, those patients who developed IDC, and who did not have a good clinical response, death occurred in 1 year or more [10].

The etiology of both is unknown and the relationship between them remains unclear. A reduction in cardiomegaly and an improvement in cardiac function occur in about $50 \%$ or more of patients with PC. However, those patients who develop IDC, improvement of cardiac function is less common [10].

During pregnancy, there is an increase in cardiac output and blood plasma volume. Under these conditions, the IDC patients can develop deterioration of cardiac function and maternal death. Given these circumstances, obstetricians and cardiologists must make the difficult decision to terminate the pregnancy or not $[1,6]$. In the case presented, due to the unfavorable evolution of the patient, it was chosen by resolution of pregnancy. Some cases reported in the literature showed similar outcome [4-6].

The treatment of IDC is based on the treatment of symptoms of cardiac insufficiency and the prevention of complications such as thromboembolic and organ dysfunction, avoiding drugs which have the potential teratogenic effects as inhibitors of angiotensin converting enzyme. Medications such as beta blockers, loop diuretics, vasodilators (hydralazine or nitrates) and digitalis (digoxin) are well tolerated during pregnancy. The nonpharmacological treatment suggested for this period should include sodium and water restriction and moderate exercise [1-3].

IDC patients have an increased risk for thromboembolism and prophylaxis is recommended in the literature [1,3,4]. In 1999, Chan et al. reported the case of a young woman of 27 years who developed IDC at 18 weeks of gestation and evolved with an embolic stroke postoperative cesarean section, despite the use of prophylaxis [6].

In conclusion, although the IDC is not a very common disease, it is important that every medical professional has knowledge of its existence due to the fact this disease is set up as a cause of heart failure in pregnant women, enabling the physician to the diagnosis and early treatment.

The physician should be alert to possible complications, such as thromboembolic events and should always investigate the presence of cardiac thrombi and institute full anticoagulation with lower risk of thromboembolism.

\section{REFERENCES}

[1] Regitz-Zagrosek, V., Lundqvist, C.B., Borghi, C., Cifkova, 
R., Ferreira, R., Foidart, J.-M., et al. (2011) ESC guidelines on the management of cardiovascular diseases during pregnancy. European Heart Journal, 32, 3147-3197. doi:10.1093/eurheartj/ehr218

[2] Jefferies, J.L. and Towbin, J.A. (2010) Dilated cardiomyopathy. The Lancet, 375, 752-762. doi:10.1016/S0140-6736(09)62023-7

[3] Mohan, S.B., Parker, M., Wehbi, M. and Douglass, P. (2002) Idiopathic dilated cardiomyopathy: A common but mystifying cause of heart failure. Cleveland Clinic Journal of Medicine, 69, 481-487. doi:10.3949/ccjm.69.6.481

[4] Dando, J. and D’souza, D. (2006) Antenatal idiopathic dilated cardiomyopathy. Journal of Obstetrics \& Gynaecology, 26, 164-165. doi:10.1080/01443610500460059

[5] Koželj, M., Novak-antolic, Ž., Noc, M. and Antolic, G. (2003) Idiopathic dilated cardiomyopathy in pregnancy. Acta Obstetricia et Gynecologica Scandinavica, 82, 389390.

[6] Chan, F. and Kee, W. (1999) Idiopathic dilated cardio- myopathy presenting in pregnancy. Canadian Journal of Anesthesia, 46, 1146-1149. doi:10.1007/BF03015524

[7] Mazor, M., Levitas, E., Gussarsky, Y., Friedman, S. and Leiberman, J.R. (1994) Idiopathic dilated cardiomyopathy in pregnancy. Archives of Gynecology and Obstetrics, 255, 51-53. doi:10.1007/BF02390676

[8] Stewart, G.C. (2012) Management of peripartum cardiomyopathy. Current Treatment Options in Cardiovascular Medicine, 14, 622-636. doi:10.1007/s11936-012-0210-9

[9] Karaye, K.M. and Henein, M.Y. (2013) Peripartum cardiomyopathy: A review article. International Journal of Cardiology, 164, 33-38. doi:10.1016/j.ijcard.2011.11.069

[10] Van Hoeven, K.H., Kitsis, R.N., Katz, S.D. and Factor, S.M. (1993) Peripartum versus idiopathic dilated cardiomyopathy in young women-A comparison of clinical, pathologic and prognostic features. International Journal of Cardiology, 40, 57-65. doi:10.1016/0167-5273(93)90231-5 